Çukurova Üniversitesi Mühendislik Mimarlık Fakültesi Dergisi, 31(ÖS 1), ss. ÖS 109- ÖS 115, Ağustos 2016

Cukurova University Journal of the Faculty of Engineering and Architecture, 31(ÖS 1), pp. SI 109-SI 115, August 2016

\title{
Elektrofüzyon Kaynaklı Polietilen 80 Kalite Doğalgaz Borularının Tokluğu
}

\author{
Asghar NAJAFIGHAREHTAPEH ${ }^{* 1}$, Ramazan KAÇAR ${ }^{2}$ \\ ${ }^{I}$ Sakarya Üniversitesi, Fen Bilimleri Enstitüsü, İmalat Mühendisliği Ana Bilim Dal, Sakarya \\ ${ }^{2}$ Karabük Üniversitesi, Teknoloji Fakültesi, İmalat Mühendisliği Bölümü, Karabük
}

Geliş tarihi: 13.01.2016 Kabul tarihi:30.04.2016

\section{Özet}

Farklı standartlarda polietilen boruların elektrofüzyon kaynaklı birleştirmeleri $-5^{\circ} \mathrm{C}$ ile $+30^{\circ} \mathrm{C}$ sıcaklık aralığında yapılması önermektedir. Ancak iklim şartları düşünüldüğünde özellikle soğuk ülkelerde ve acil durumlarda belirtilenden daha düşük çevre sıcaklığında kaynak gerçekleştirildiğinde birleştirmenin tokluğu üzerinde detaylı bir çalı̧̧maya ihtiyaç vardır. Bu amaçla orta yoğunluklu polietilen (PE80) borular elektrofüzyon kaynak yöntemi ile oda sıcaklığı, $0^{\circ} \mathrm{C}$ ve $-30^{\circ} \mathrm{C}$ sıcaklıkta temin edildiği şekliyle birleştirilmiştir. Birleştirmelere izod darbe deneyi testi uygulanmış ve kırık yüzey incelemesi gerçekleştirilmiştir. Sonuç olarak birleştirmelerin darbe dayanımını birleştirme çevre sıcaklığından etkilendiği belirlenmiştir.

Anahtar Kelimeler: Orta yoğunluklu polietilen, Elektrofüzyon kaynağı, Çevre sıcaklığı, Tokluk

\section{The Toughness of Electrofusion Welded PE 80 Quality Natural Gas Pipes}

\begin{abstract}
Standards used in electrofusion welding of polyethylene(PE) pipes, recommends to be carried out at the temperature range between $-5^{\circ} \mathrm{C}$ and $+30^{\circ} \mathrm{C}$. However, when climatic conditions considered especially in cold countries and emergency situations when the welding process performed at lower ambient temperatures than specified; we need a detailed study about toughness of the weldments. For this purpose, medium density (PE80) pipes were joined with electrofusion welding method at the various environment temperatures (room temperature, $0^{\circ} \mathrm{C}$ and $-30^{\circ} \mathrm{C}$ ) as recieved. The impact resistance of weldments were investigated by Izod impact test and fracture surface inspection was carried out. As a result, the weldments impact resistance was determined to be affected by the ambient temperature.
\end{abstract}

Keywords: Medium density polyethylene, Electrofusion welding, Ambient temperatures, Toughness

\footnotetext{
* Sorumlu yazar (Corresponding author): Asghar NAJAFIGHAREHTAPEH, Sakarya Üniversitesi, Fen Bilimleri Enstitüsü, Imalat Mühendisliği Ana Bilim Dall, Sakarya.najafi.asghar@yahoo.com
} 


\section{GíRiş}

Termoplastikler içerisinde polietilenler (PE) ekonomikliği, iyi mekanik ve korozyon özellikleri sebebiyle ilgi çekici malzemelerdir [1-4]. Diş ortam uygulamaları için oldukça iyi potansiyele sahipler. Temelini hidrokarbonların oluşturduğu polietilenler etilen moleküllerinin molekül zincirleri şeklinde bağlanmasıyla oluşan plastik malzemelerdir [2,4]. Yapısal olarak kısmi kristal malzeme sınıfinda yer alırlar. Yapıdaki kristalin miktarı, moleküllerin özgül ağırlığına ve yönlenmelerine bağlı olarak değişir [5]. Kristal yap1; molekül zincirlerinin bir araya gelerek yönlenmesiyle lamellerden ve lamellerinde bir araya gelerek oluşturduğu "spherulite"lerden meydana gelir [6-8]. Kristal miktarı malzemenin dayanımının ve sertliğinin bir göstergesidir. Amorf yap1 oranının yüksek olması malzemenin düşük dayanımlı ve daha sünek olması anlamını ifade etmektedir [5].

Polietilenler (PE) yoğunluklarına göre düşük yoğunluklu polietilen (DYPE), lineer düşük yoğunluklu (LDYPE), orta yoğunluklu polietilen (OYPE) ve yüksek yoğunluklu polietilen (YYPE) diye sinıflandırılmaktadır [9]. Orta yoğunluklu polietilen (OYPE) yoğunluğu 0,925-0,94 gr/ $\mathrm{cm}^{3}$ arasında olup, yüksek veya düşük basınç proseslerinde elde edilir. Modern alt yap1 sistemlerin imalatında, özellikle doğal gaz ve suyun taşınması veya dağıtılmasında orta yoğunluklu polietilen borular tercih edilmektedir [1].

Artan taleple beraber plastik malzemelerinin kaynaklı birleştirmeleri gündeme gelmiştir. PE boruların birleştirilmesinde en çok kullanılan alın ve elektrofüzyon olmak üzere iki çeşit kaynak yöntemi mevcuttur [2-4]. Doğalgaz dağıtım hatlarında daha emniyetli olduğu için elektrofüzyon kaynağı kullanılır [1-2]. Bu yöntemde borular manşon denilen birleştirme elemanı kullanarak dış yüzeyden birbirine kaynatılırlar. Bağlantı elemanları içine yerleştirilmiş rezistans sarg1 tellerine uygun bir gerilim ve akım verilerek, tellerin 1sıtılması sonucu bağlantı elemanı iç yüzeyindeki PE malzeme ile borunun dış yüzeyindeki tabakanın erimesi sonucu birleşme sağlanır [1,3]. Elektrofüzyon kaynak yöntemi, kuluçka, birleşme ve sağlamlaşma, plato ve soğuma aşaması olmak üzere dört kaynak zamanından oluşur. Daha fazla 1s1 girdisi devamında ise yapıda bozulma süreci başlar [5]. Elektrofüzyon kaynak yöntemi aşamaları şematik olarak Şekil 1'de gösterilmiştir.

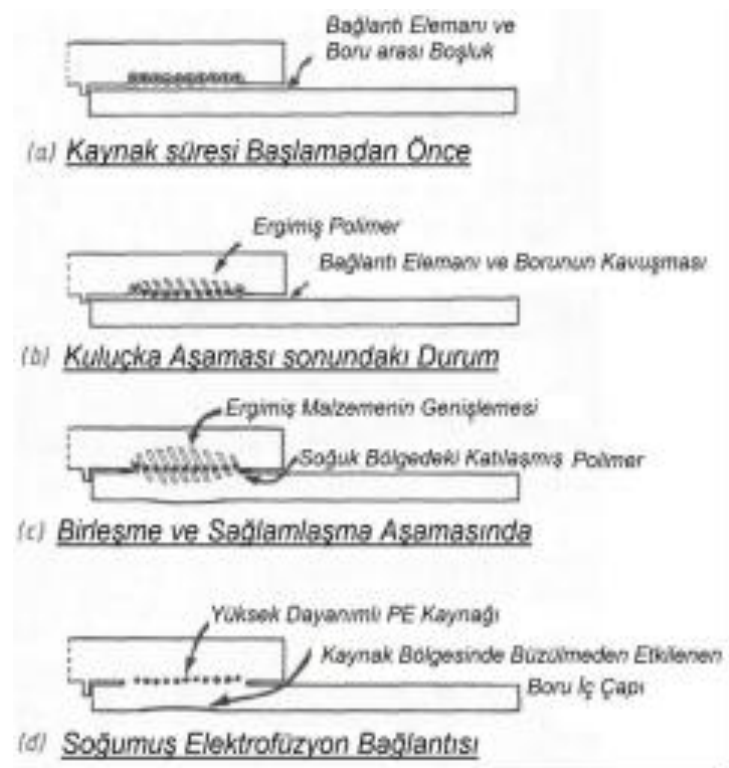

Şekil 1. Elektrofüzyon kaynak yöntemindeki aşamaların şematik göstergesi [10]

Literatür araştırmalarında PE borularla ilgili kaynak yöntemleri ve bilhassa elektrofüzyon kaynak uygulamaları ilgili çalışmalara rastlanmaktadır [1-3,5,7-10]. Ancak uygulamadaki çevresel faktörlerin belirlenmesi ve kaynak sonrası birleştirmenin özelliklerini iyileştirme çalışmaları hala devam etmektedir.

PE doğal gaz boru elektrofüzyon kaynaklı birleştirmelerin standartlarda $-5^{\circ} \mathrm{C}$ ile $\quad+25^{\circ} \mathrm{C}$ sıcaklık aralığında yapılması önerilmektedir [2,3]. Bir başka standartta $+3^{\circ} \mathrm{C}$ üzerindeki sicaklıklarda birleştirmenin yapılması gerekliliğini vurgulanmıştır [11]. DVS 2207 göre ise birleştirme sıcaklık aralığı ise +5 ile $+50^{\circ} \mathrm{C}$ olarak ifade edilmiştir [2,3,12]. Tokluk malzemelerin en önemli özelliklerinden sayılmaktadır ve genellikle darbe dayanım testleri ile ölçülmektedir. Darbe 
testi polimerin ani darbe karşısında kırılma davranışını belirler.

Test için levha halinde üzerine çentik açılmış standart numune kullanılır [13]. Polimerlerin darbe direncini etkileyen önemli bir faktörde sıcaklıktır. $\mathrm{Bu}$ sebeple deneysel çalışmalar çoğunlukla oda sıcaklığında gerçekleştirilir. Buna rağmen polimerik malzemelerin çevre koşullarına göre farklı sicaklıklarda darbeye maruz kalma ihtimalleri de düşünülmesi gerektiğinden farklı sıcaklıklardaki darbe dirençlerinin de bilinmesi gerekir [14-17]. Bu sebeple iklim şartları ve çevre koşulları düşünüldüğünde özellikle soğuk ülkelerde ve acil durumlarda belirtilenden daha düşük sıcaklıklarda kaynak gerçekleştirildiğinde birleştirmenin özellikleri üzerinde detaylı bir çalışmaya ihtiyaç vardır. Bu amaçla doğalgaz dağıtım hatlarında kullanılan polietilen (PE80) borulara uygulanan elektrofüzyon kaynağında çevre sıcaklığının birleştirmenin özellikleri üzerindeki etkisi etraflıca araştırılmıştır. Farklı çevre sıcaklıklarında (oda sıcaklığ $1,0^{\circ} \mathrm{C}$ ve $-30^{\circ} \mathrm{C}$ ) temin edildiği şekliyle birleştirilen PE80 borulara standartlarda göre darbe testi uygulanmıştır.

\section{DENEYSEL METOT}

\subsection{Malzeme}

Çalışmada özellikleri Çizelge 1'de verilen $10 \mathrm{~mm}$ et kesit kalınlığına sahip, Ø110 mm çapında ve $220 \mathrm{~mm}$ boyunda, OYPE (PE80 kalite) boru alın alına birleştirilmesi için bağlantı elemanı kullanılmıştır. PE80 boru ve bağlantı elemanı Şekil 2'de gösterilmiştir.

Çizelge 1. PE80 boru ve bağlantı elemanlarının özellikleri

\begin{tabular}{|c|c|c|c|}
\hline \multirow{2}{*}{ Malzeme } & $\begin{array}{c}\text { Yoğunluk } \\
\left(\mathrm{kg} / \mathrm{m}^{3}\right)\end{array}$ & $\begin{array}{c}\text { Akma } \\
\text { katsayısı } \\
\left(190^{\circ} \mathrm{C},\right. \\
5 \mathrm{~kg})\end{array}$ & $\begin{array}{c}\text { S1caklık } \\
\text { dayanımı } \\
(\mathrm{OIT} \\
\left.200^{\circ} \mathrm{C}\right)\end{array}$ \\
\hline PE80 & 94 & 0,4 & $\geq 20 \mathrm{~min}$ \\
\hline
\end{tabular}

\subsection{Boruların Kaynak Öncesi Hazırlığı}

Şekil 2'de gösterildiği gibi kesme makası ile dik olarak kesilen boruların bağlantı elemanının içerisine girecek kısmı mengeneye sabitlenerek yüzeyinden uygun bir kazıyıc1 ile homojen bir şekilde 0,2 mm derinlikte oksit tabakası kazınarak keten bir bezle silinerek iyice temizlenmesine özen gösterildi. Temizlenen boru bağlantı elemanı içerisine yerleştirildikten sonra konum sabitleyiciye doğru bir şekilde tutturuldu.

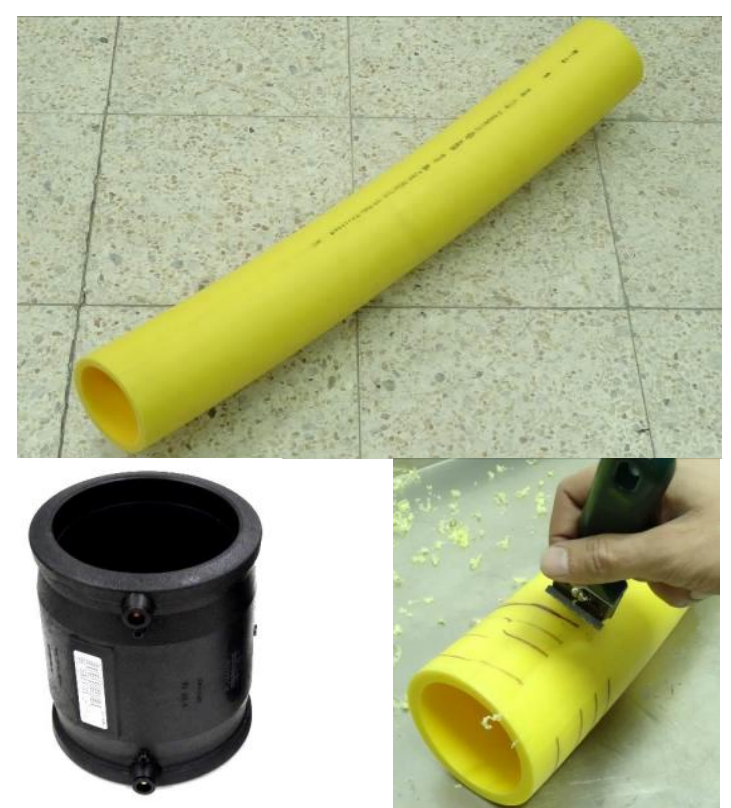

Şekil 2. PE80 boru, bağlantı elemanı ve kazıma işlemi

\subsection{PE80 Borularının Birleştirilmesi}

Birleştirilme öncesi kaynak makinesinin kalibrasyonu gerçekleştirildikten sonra bağlantı elemanının özellikleri bir barkot okuyucu sistemle kaynak makinesine aktarıldı. Bu özelliklere uygun çevre sıcaklığını hesaba katarak üzerinden elektrik akımı geçirilen rezistans bakır tellerin ısınmasıyla bağlantı elemanının iç yüzeyi ile borunun dış yüzeyi arasında bir bağ oluşturmaya yetecek süre makine tarafindan ayarlanarak uyguland. Şekil 3'de çalışmada kullanılan elektrofüzyon kaynak makinesi ve boru konum sabitleyici gösterilmiştir. 


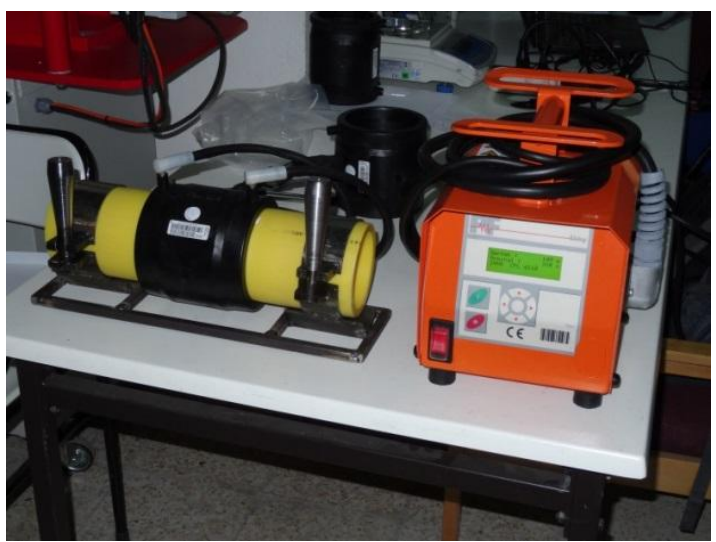

Şekil 3. Elektrofüzyon kaynak makinesi, boru konum sabitleyici

Çalışmanın amaçlarından birisi çevre sıcaklığının PE80 boruların kaynak kabiliyetine etkisinin belirlenmesi olduğu için düşük çevre sıcaklıklarında birleştirilecek borular konumlandırıcıya yerleştirilmiş durumda ve kaynak makinesiyle birlikte iki saat derin dondurucuda istenilen çevre sicaklığında bekletildi. Böylece makine tarafindan birleştirme için çevre sıcaklığına uygun zaman dilimi akım geçmesine müsaade edilerek borular birleştirilmiştir. Kaynaktan sonra borular 15 dakika soğutularak bağlantı elemanının soketinden kaynak makinesi ayrılmış ve 30 dakika boruların konumlandırıcı üzerinde kalmasına müsaade edilmiştir. Daha sonra borular numaralandırılarak teste hazır boyutlarda numuneler haline getirilmiştir.

\section{4. İzod Darbe Testi}

Elektrofüzyon kaynaklı doğalgaz borularının ani bir kuvvet altındaki davranışları darbe çentik deneyi ile belirlenir. Bu amaçla çalışmada ASTM D256 standardına göre kaynaklı birleştirmelerden deney numuneleri hazırlanarak izod darbe testine tabi tutulmuştur [13]. Numuneler rezistans direnç telleri tam ortaya gelecek şekilde yarısı bağlantı elemanından ve yarısı borudan oluşacak şekilde ASTM D256 standardında belirtilen boyutlarda $(12,7 \times 12,7 \times 63,5 \mathrm{~mm})$ hazırland1 (Şekil 4). Rezistans direnç tellerinin etkisini minimize etmek için iki tel arasından $2.54 \mathrm{~mm}$ derinlikte ağız açısı $45^{\circ}$ çentik açıldı.

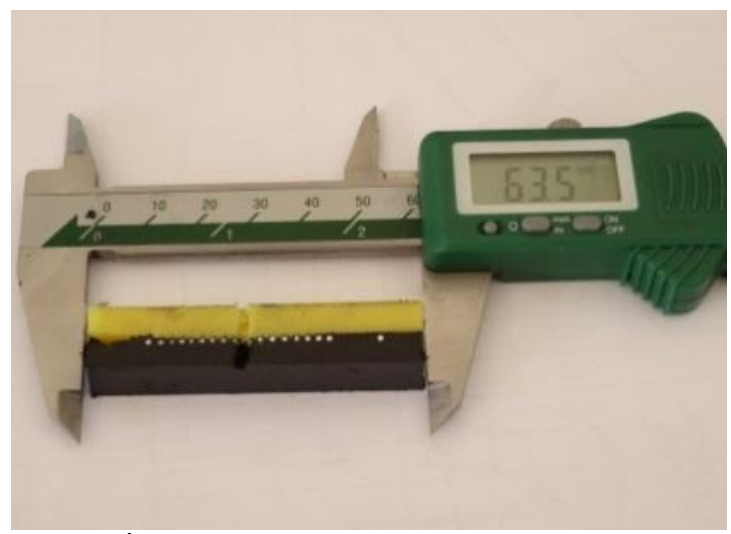

Şekil 4. İzod darbe test numunesi

\subsection{1. İzod Darbe Deneyinin Uygulanması}

Bu deney yöntemini uygulamak için darbe çentik test cihazından yararlanılmıştır (Şekil 5). Kaynaklı birleştirmelerin kırılmasında 24J enerji uygulayan çekiçten yararlanılmıştır. Deney numunelerini tutucu mengeneye dik bir şekilde tutacak tutucu kalıp hazırlanarak darbe çentik deney cihazına sabitlenmiştir. Deney numunesini kırmak için üretilen 24J darbe enerjisi sağlayan çekiç ve numune tutucusu Şekil 5'de gösterilmiştir.
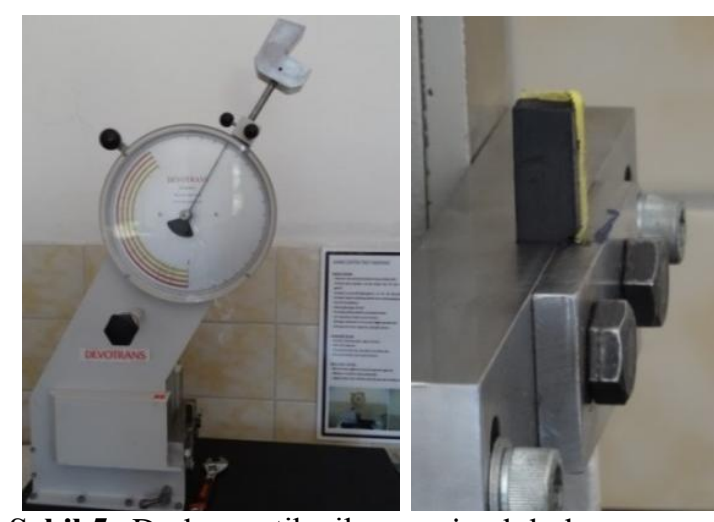

Şekil 5. Darbe çentik cihazı ve izod darbe numune tutucusu

Şekil 5'de gösterildiği ve standartta belirtildiği gibi çentik çekice bakacak şekilde ve çekiç 
çentikten $22 \mathrm{~mm}$ daha yukarıya vurdurularak numuneler kırılmıştır. Her bir parametre için sekiz numune oda sıcaklığında test edilmiştir. Daha sonra numuneyi kırmak için harcanan enerji numune kesit alanına oranlanarak, numunelerin darbe emme enerjisi hesaplanmıştır. Ancak çalışmada sonuçların tutarlılığ 1 açısından birbirine en yakın dört numune ortalamasından yararlanılmıştır.

\subsection{2. İzod Darbe Deney Numunelerinin Kırılma Yüzey İncelenmesi}

Deney numunelerinin kırık yüzey incelemesi de gerçekleştirilmiştir. İnceleme öncesi deney numuneleri kırık yüzeyi içerisine alacak şekilde $15 \mathrm{~mm}$ uzunluğunda kesildikten sonra iletkenliği sağlamak amaciyla yüzeyi paladyum tozu ile kaplanmıştır. Numuneler Carl Zeiss marka SEM mikroskobu ile incelenmiştir.

\section{SONUÇLAR VE TARTIŞMA}

\subsection{PE80 Doğal Gaz Borularının Çevre Sıcaklığı İle Kaynak Zamanı İlișkisi}

Elektrofüzyon kaynak yöntemi ile birleştirilen OYPE80 doğal gaz borularının çevre sıcaklığına bağlı olarak birleştirme sırasında kaydedilen kaynak süreleri Şekil 6a'da grafiksel olarak gösterilmiştir.

\section{2. Çevre Sıcaklığının PE80 Birleștirmelerinin Darbe Dayanımına Etkisi}

Çalışmada farklı çevre sıcaklığında birleștirilen PE80 doğal gaz boru kaynaklı birleştirmelerinin izod darbe deney sonucu grafiksel olarak Şekil $6 b$ 'de gösterilmiştir.

Şekil 6a'dan görüldüğü gibi azalan çevre sıcaklığg ile birlikte PE80 birleştirmesi için gerekli kaynak süresinin değiştiği tespit edilmiştir. Düşük çevre sıcaklıklarında birleştirilen boruların kaynak süresinin daha fazla olduğu görülmektedir. Oda sıcaklığı ile $30{ }^{\circ} \mathrm{C}$ çevre sıcaklığında birleştirilen numunelerin kaynak zamanında 25 saniye gibi bir fark oluştuğu tespit edilmiştir. $\mathrm{Bu}$ farkın oluşmasında etkin olan husus kaynak yönteminden kaynaklandığı düşünülmektedir.

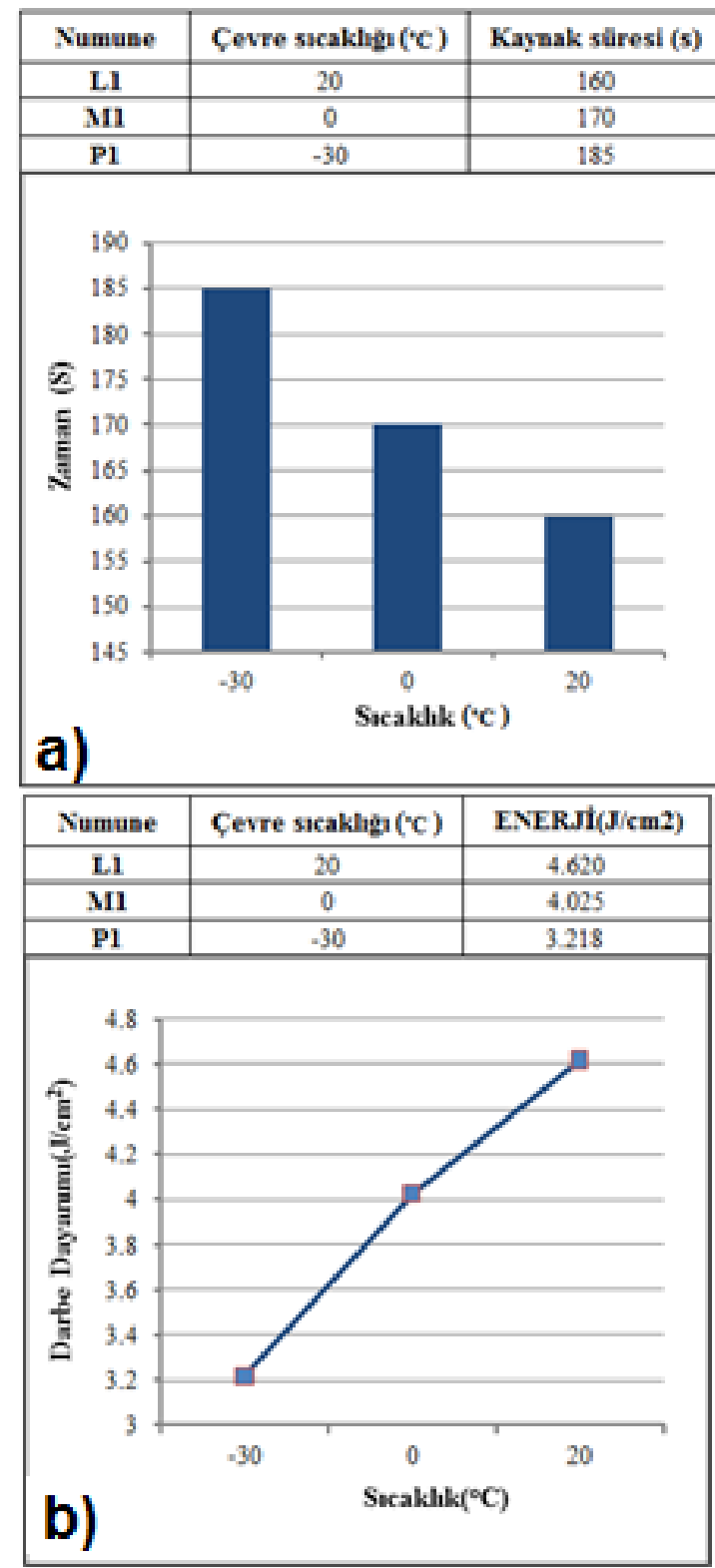

Şekil 6. Çevre sıcaklığının a) kaynak süresi,

b) darbe dayanımına etkisi

Çünkü elektrofüzyon kaynak işleminde birleştirme için gerekli parametreler manşon üzerindeki üretici firmanın önerdiği unsurlar bir barkod okuyucu ile 
makineye aktarıldıktan sonra kaynak makinesi sıcaklık sensörü çevre sıcaklığını da dikkate alarak bir kaynak zamanı belirler. Bu sebeple daha düşük çevre sıcaklıklarında birleştirilecek numuneler için azalan çevre sıcaklığıyla birlikte kaynak makinesi daha uzun kaynak zamanı tanımlamaktadır. Birleştirme kaynak zamanının azalan çevre sıcaklığıyla değiştiği başka çalışmalarda da rapor edilmiştir [2,3].

Şekil $6 b$ ise numunelerin darbe dayanımının azalan çevre sıcaklığından olumsuz olarak etkilendiğine işaret etmektedir. En yüksek darbe dayanımı oda sicaklığında birleştirilen numunede tespit edilirken, en düşük darbe dayanımı ise $-30^{\circ} \mathrm{C}$ çevre sicaklığında birleştirilen numunede tespit edilmiştir. Genel eğilim azalan çevre sıcaklığıyla deney numunelerinin darbe dayanımının azalması yönündedir. $\mathrm{Bu}$ durum PE80 borunun özellikleri ve yapısıyla ilişkili olduğu düşünülmektedir. Çentik açısı da sonuçlar üzerinde etkili olan bir diğer parametre olarak düşünülebilir.

Çalışmada oda sıcaklığında, $0^{\circ} \mathrm{C}$ ve $-30^{\circ} \mathrm{C}$ çevre sıcaklıklarında birleştirilen PE80 doğalgaz borularının darbe deney numunelerinin kırılma yüzeyi SEM mikroskobu ile incelenmiştir. Kırık yüzey görüntüleri Şekil 7'de gösterilmiştir.

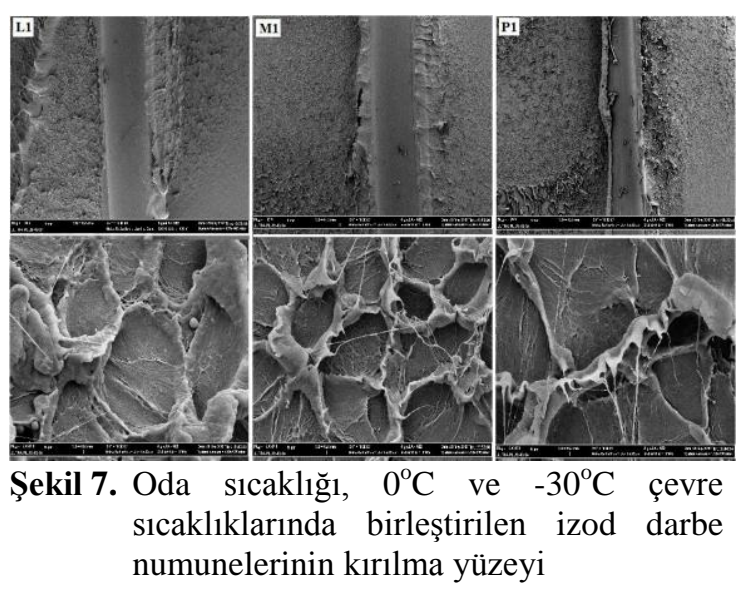

Şekil 7'den görüldüğü gibi oda sıcaklığında birleştirilen numunenin kaynak bölgesindeki daha fazla kristalin miktarına bağlı olarak gevrek kırılma davranışıyla kopmanın meydana geldiğine işaret etmektedir. Azalan çevre sıcaklığıyla kaynak bölgesinin yapısındaki kristalin miktarı azalmasına bağlı olarak daha sünek bir kırılma davranışıyla kırılmanın gerçekleştiği görülmektedir. Amorf bölgedeki lif şeklindeki uzamalar numunelerin sünekliğinin göstergesidir. Darbe dayanımın sünek malzemelerde daha düşük bulunmasının sebebi numuneyi kırmak için açılan çentik açısıyla da alakalı olabilir. Ayrıca yüksek çevre sıcaklıklarında birleştirilen numunelerin yapısındaki amorf bölge ile çevrelenmiş sert kristalin etki eden darbe kuvvetini daha fazla absorbe etmesinden dolayı darbe dayanımının daha yüksek bulunmasına neden olabilir.

Sonuçlar deney numunelerinin darbe dayanımının azalan çevre sicaklığından olumsuz olarak etkilendiğine işaret etmektedir. PE80'de en yüksek darbe dayanımı oda sıcaklığında birleştirilen numunede tespit edilirken, en düşük darbe dayanımı $-30^{\circ} \mathrm{C}$ çevre sıcaklığında birleştirilen numunede tespit edilmiştir. Çevre sıcaklığgiyla deney numunelerinin darbe dayanımının azaldı $\breve{g}_{1}$ net olarak görülmektedir. Azalan çevre sıcaklığıyla darbe dayanımının azalmasında küçük boyutlu kristalinlerin etrafını çevreleyen ince sünek amorf tabakanın darbe etkisini yeterince absorbe edememesinden kaynaklandığı düşünülmektedir. Yüksek çevre sıcaklığında birleştirilen numunelerin yapısındaki kaba kristalinlerin etrafındaki kalın amorf tabaka darbe etkisini daha fazla sönümleyerek darbe tokluğunun daha yüksek bulunmasının sebebi olarak düşünülmektedir.

\section{GENEL SONUÇLAR}

- Elektrofüzyon kaynağıyla birleştirilen OYPE80 boruların kaynak zamanı azalan çevre sıcaklığı ile arttığ 1 tespit edildi.

- PE80 birleştirmeleri için azalan çevre sıcaklığıyla kaynak bölgesinin yapısındaki kristalin miktarının azalmasına bağlı olarak, diğer bir ifadeyle bölgedeki artan amorf yap1 miktarıyla ilişkili olarak daha sünek bir kırılma davranışıyla kırılmanın gerçekleştiği görülmektedir. $\mathrm{Bu}$ durum düşük çevre sıcaklıklarında birleştirilen numunelerin kristalin çekirdeklenme sayısının artışına neden 
olurken onu çevreleyen amorf yapı hacim oranının artmasına fakat amorf katman kalınlığının incelmesine neden olarak darbe etkisini yeterince absorbe edemez duruma getirdiği düşünülmektedir.

\section{TEŞEKKÜR}

Bu çalışma Karabük üniversitesi proje destek ofisi ve Karabük Kargaz doğalgaz dağıtım firması ve 2K Welding Teknoloji Makine İmalat Müh. Taahhüt San. ve Tic. Ltd. Şti. tarafindan desteklenmiştir. Adı geçen kurum ve kuruluşlara teşekkür edilir.

\section{KAYNAKLAR}

1. Weissbach, W., 2007. Materials Science and Materials Testing, Verlag, Taschenbuch, Vieweg \& Teubner.

2. Akkurt, A., 2014. An Analysis Of Electromelting and Hot Element Welding Method's Safety Used to Join PE Natural Gas Pipes, International Journal of Electronics, Mechanical and Mechatronics Engineering, Vol. 3, No 2, 493-504.

3. Akkurt, A., ve Saraç, E., 2012. Farklı Ortam Sıcaklıklarında Elektroergitme Kaynağı ile Birleştirilen PE Doğalgaz Transfer Hatlarının Güvenirliklerinin Araştırılması, Electronic Journal of Machine Technologies, Vol. 9, No 2, 39-52.

4. Akkurt, A., ve Ertürk, İ., 2010. Sicak Elaman Alın Kaynak Yöntemi ile Birleştirilen PE Doğalgaz Borularının Güvenirliklerinin Araştırılması, Pamukkale Üniversitesi Mühendislik Bilimleri Dergisi, Vol. 16, No 2, 221-233.

5. Bowman, J., 1997. A Review of The Electrofusion Joining Process For Polyethylene Pipe Systems, Polymer Engineering and Science, Vol. 37, No 4, 674-691.

6. Joy, J.J., 2008. Mechanical and Chemical Properties of High Density Polyethylene: Effects of Microstructure on Creep Characteristics, Doctoral Thesis, University of Waterloo.
7. Say, S.S., ve Akgüngör, A.A., 2009. Welding Defects and Their Reasons Observed in Electrofusion Welding of Polyethylene Pipes, 24th World Gas Conference, WGC Argentina.

8. Hiroyuki, N., Fumio, I., Akio, N., and Testuo, I., 1994. Design of Electrofusion Joints and Evaluation of Fusion Strength Using Fusion Simulation Technology, Polymer Engineering and Science, Vol. 34, No 20, 1529-1534.

9. Stakenborghs, R., ve Rouge, B., 2009. Microwave Based NDE Inspection of HDPE Pipe Welds, The 17th International Conference on Nuclear Engineering, Brussels, Belgium.

10. Fujikakef, M., Fukumurat, M., ve Kitao, K., 1997. Analysis of the Electrofusion Joining Process In Polyethylene Gas Piping Systems, Computer and Structures, Vol. 64, No 5/6, 939948.

11. Iranian Gas Standards, IGS-C-DN-001, Code of Practice for Construction and Commissioning of P.E. Gas Networks.

12. DVS 2207-1 Standard, Supplement, Welding of Thermoplastics - Heated tool welding of pipes, pipeline components made of PE-HD.

13. ASTM-D256-10: 2010. Standard, Test Methods For Determining The Izod Pendulum Impact Resistance of Plastics.

14. Boyer, S.A.E., and Haudin, J.-M., 2010. Crystallization of Polymers at Constant and High Cooling Rates: A New Hot-Stage Microscopy Set-UPQ, Polymer Testing, Vol. 29, 445-452.

15. Strobl, G., 2006. Crystallization and melting of bulk polymers: New observations, conclusions and a thermodynamic scheme, Progress in Polymer Science. Vol 31, 398-442.

16. Wang, L.Y., Lugito, G., Woo, E.M., and Wang, Y.H., 2012. Phase behavior, polymorphism and spherulite morphology in Poly (1,4-butylene adipate) interacting with two structurally similar acrylic polymers, Polymer, Vol. 53, 3815-3826.

17. Weissbach, W., 2007. Materials Science and Materials Testing, Verlag, Taschenbuch, Vieweg \& Teubner. 
